\title{
All type B aortic dissections should undergo thoracic endovascular aneurysm repair
}

\author{
Saket Singh, MS, MCh, ${ }^{\mathrm{a}}$ Naiem Nassiri, MD, RPVI, ${ }^{\mathrm{b}}$ and Prashanth Vallabhajosyula, MD, $\mathrm{MS}^{\mathrm{a}}$
}

With rapid advances in thoracic endovascular aneurysm repair (TEVAR) technology, and with increasing adoption of this procedure by the cardiovascular community, its role in the management of type B aortic dissection (TBAD) continues to evolve. Traditionally, medical management with anti-impulse therapy has been advocated for TBAD. In a retrospective study of 100 consecutive patients with TBAD, the early survival rate was as high as $91 \%{ }^{1}$ This study also reported that $66 \%$ of these survivors had an uncomplicated long-term course with anti-impulse therapy. However, the 5-year survival of patients with TBAD receiving the best medical treatment (BMT) is only $60 \%$ to $80 \%$. ${ }^{2}$ Continued degeneration of the aorta and resulting dilatation of the false lumen have been responsible for this suboptimal long-term result. We know that the descending thoracic aorta (DTA) growth rate exceeds that of the ascending aorta and that the dissected aorta tends to degenerate quicker than an aneurysmal aorta, ${ }^{3}$ resulting from dilatation of false lumen, which can be seen in $50 \%$ of patients with TBAD over 5 years. ${ }^{4}$ Aortic rupture, however less common in TBAD compared with type A aortic dissection, remains the most common cause of mortality in TBAD. ${ }^{5}$ The incidence of aortic rupture increases up to $30 \%$ per year when the aortic diameter reaches $6 \mathrm{~cm} .{ }^{5}$ These findings speak to the persistent, long-term morbidity and mortality associated with the TBAD event. Expert consensus has been to have a "complication-specific" approach when treating TBAD mainly because of the benign natural history of a major subgroup of patients with TBAD, ${ }^{6,7}$ and poor results after open repair. Pooled operative mortality after open repair of TBAD is $17.5 \%$, with an increase to $30 \%$ in complicated TBAD cases, and reaches up to $50 \%$ in the presence of malperfusion. ${ }^{8}$

In a review of 1129 consecutive patients with TBAD from the International Registry of Acute Aortic Dissection, in which 853 patients received medical treatment and 276

\footnotetext{
From the ${ }^{\mathrm{a} D i v i s i o n}$ of Cardiac Surgery, and ${ }^{\mathrm{b}}$ Division of Vascular and Endovascular Surgery, Department of Surgery, Yale University School of Medicine, New Haven, Conn.

Received for publication Dec 8, 2020; accepted for publication May 25, 2021; available ahead of print Aug 9, 2021

Address for reprints: Prashanth Vallabhajosyula, MD, MS, Division of Cardiac Surgery, Yale University School of Medicine, Boardman Building 204, 330 Cedar St, New Haven, CT 06510 (E-mail: prashanth.vallabhajosyula@yale.edu).

JTCVS Techniques 2021;9:17-24

2666-2507

Copyright (c) 2021 The Author(s). Published by Elsevier Inc. on behalf of The American Association for Thoracic Surgery. This is an open access article under the CC BY-NC-ND license (http://creativecommons.org/licenses/by-nc-nd/4.0/).

https://doi.org/10.1016/j.xjtc.2021.05.029
}

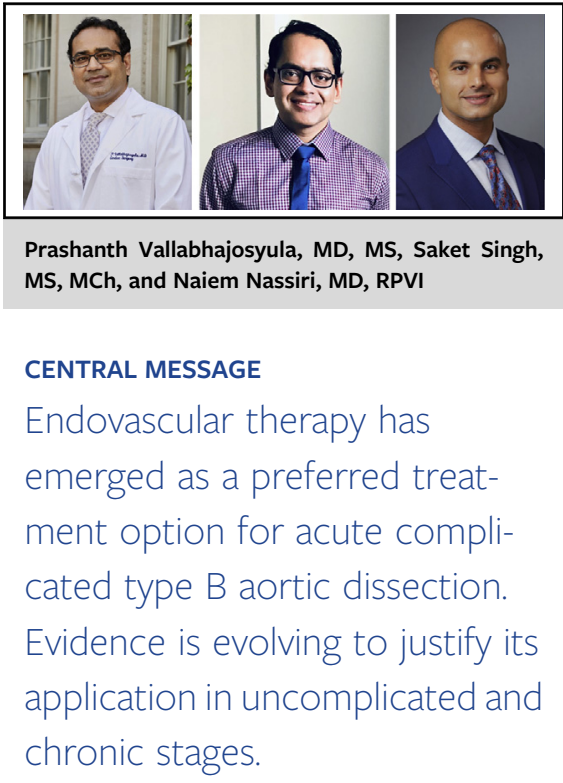

patients underwent TEVAR, in-hospital mortality $(8.7 \%$ vs $10.9 \% ; P=.273)$ and 1 -year mortality $(9.8 \%$ vs $8.1 \% ; P=.604)$ were similar between the 2 treatment groups. ${ }^{9}$ The TEVAR group at presentation had more inhospital morbidity with an increased incidence of acute kidney injury (medical $12.5 \%$ vs TEVAR $25.3 \% ; P=.016$ ) and extension of dissection $(5.8 \%$ vs $10.2 \% ; P<.001)$. This review, which had a significantly greater number of patients with complicated dissections in the TEVAR group $(37.2 \%$ vs $61.7 \%)$, showed a significant decrease in the size of DTA with TEVAR at 5-year follow-up. Aortic remodeling after TEVAR translated into less death rate in the TEVAR group at 5 years $(29 \%$ vs $15.5 \% ; P=.018)$. There was no difference between the 2 groups in the incidence of new dissection, extension of dissection, or late intervention. Five-year results of the INSTEAD XL (Investigation of Stent Grafts in Aortic Dissection) trial, a randomized trial comparing medical management with additional TEVAR in patients with uncomplicated TBAD, showed significant reduction in aorta-specific mortality in the TEVAR group (TEVAR: $0 \%$ vs medical treatment: $16.9 \% ; P<.0005) .{ }^{10}$ Encouraging long-term results of these investigations underscore the potential of TEVAR in TBAD management.

In this review, we make an argument for the role of TEVAR in patients with TBAD at various stages of the disease. 


\section{UNCOMPLICATED TYPE B ACUTE AORTIC DISSECTION}

Patients experience the greatest morbidity and mortality rates in the acute phase, classified as the first 2 weeks after TBAD onset. ${ }^{11,12}$ The Acute Dissection Stent Grafting or Best Medical Treatment trial (ADSORB trial) is the only prospective randomized trial comparing TEVAR with BMT in patients with acute uncomplicated TBAD. ${ }^{13}$ In this trial, after intention-to-treat analysis at the end of 1 year, none of BMT group subjects failed to reach the primary end point of freedom from false lumen thrombosis (partial or none) and aortic dilatation, compared with $50 \%$ of patients in the TEVAR group. Freedom from incomplete thrombosis of the false lumen in TBAD is important, as partially thrombosed false lumen is associated with increased aortic growth and great mortality. ${ }^{8,14}$ This trial, which was not powered to detect mortality difference, did show positive remodeling of DTA in the TEVAR group. Maximum false lumen diameter decreased by an average of $7.0 \mathrm{~mm}$ compared with an increase of $4.3 \mathrm{~mm}$ in the BMT group $(P<.001)$. Maximum true lumen diameter also showed an average increase of $8.4 \mathrm{~mm}$ in the TEVAR group compared with an increase of $1.9 \mathrm{~mm}$ in the BMT group $(P=.022)$. Overall transverse diameter of DTA also showed signs of shrinkage in the TEVAR group. This trial, in which $50 \%$ of subjects achieved targeted control of blood pressure, and $80 \%$ of patients enrolled in this study were DeBakey type IIIB, showed the benefit with TEVAR in acute uncomplicated TBAD. It is known that patients with DeBakey type IIIB TBAD have a worse prognosis than type IIIA. ${ }^{15}$

A retrospective propensity score analysis of 145 matched pairs of acute uncomplicated TBAD patients receiving either BMT alone or TEVAR showed a greater incidence of early adverse events in the TEVAR group. ${ }^{16}$ This was driven mainly by a greater incidence of type I endoleak $(8.4 \%)$ and retrograde type A dissection (TEVAR: $1.6 \%$; BMT: 0). The feasibility of TEVAR in acute TBAD was demonstrated by the ability to cover the primary tear site in $98.6 \%$ of patients with a stent graft. There was no report of paraplegia or paraparesis in the study. Although 30-day mortality was not significantly different between the 2 groups (TEVAR: $0.7 \%$ vs BMT: $2.1 \% ; P=.622$ ), all the mortality in the short term in BMT group was due to sudden aortic rupture. Five-year analysis of the matched pairs showed a significant survival benefit in the TEVAR group (freedom from all-cause death at 5 years: TEVAR 91.9\% [81.1-96.7] vs BMT 82.2\% [72.9-88.5]; $P=.028$ ). Survival benefit in the TEVAR group was mainly driven by freedom from aortic-related death at 5 years (TEVAR 94.1\% [82.998.1] vs BMT $86.1 \%$ [77.5-91.7]; $P=.044$ ). Cumulative incidence of rupture at 5 years was also greater in the BMT group (TEVAR 5.1\% [1.1-14.1] vs BMT 13.7\%
[7.8-21.3]; $P=.024)$. Both the groups had a comparable incidence of retrograde type A dissection and new dissection. Late intervention rate although greater in the BMT group, was not statistically significant (TEVAR: 6.0\% [1.9-13.3] vs BMT 9.0\% [4.6-15.1]; $P=.214$ ). There were 4 deaths reported in the BMT group after the late intervention compared with none in TEVAR group. This study showed the long-term survival benefit of TEVAR in uncomplicated acute TBAD.

Qin and colleagues, ${ }^{17}$ in their retrospective study of 338 patients with acute uncomplicated TBAD undergoing TEVAR or BMT, also showed similar early survival in both the groups. The TEVAR group had a greater incidence of early events, mainly driven by type I endoleak $(9.2 \%)$. This study found increased incidence of aortic rupture in the BMT group in the short term (TEVAR: none vs BMT: $1.9 \%$ ) and at 5-year follow-up (TEVAR: $3.3 \%$ vs BMT: $12.3 \%$ ). The BMT group also experienced greater mortality at 5 years (mortality rate from all-cause death, TEVAR: $10.8 \%$ vs BMT: $14.3 \% ; P=.010)$, and greater incidence of aortic-related adverse events (TEVAR: $28.2 \%$ vs BMT: $37.8 \% ; P=.025)$. Type I endoleak disappeared in nearly $30 \%$ of patients at long-term follow-up.

Ray and colleagues, ${ }^{18}$ in their review of 156 patients with uncomplicated TBAD, reported aortic diameter greater than $44 \mathrm{~mm}(P<.01)$ to be a strong risk factor for mortality over an average follow-up of 3.7 years. They also reported false lumen diameter greater than $22 \mathrm{~mm}$ to be a significant risk factor for decreased intervention-free survival. Elliptical configuration of the true lumen was found to be associated with increased aortic growth rate in a retrospective review of 62 patients with acute TBAD who were being medically managed. ${ }^{19}$ Tolenaar and colleagues ${ }^{19}$ also reported association of single entry tear with increased aortic growth rate (mean $5.6 \pm 8.9 \mathrm{~mm} /$ year) in patients with TBAD when compared with patients with 2 (mean $2.1 \pm 1.7 \mathrm{~mm} /$ year) or 3 entry tears (mean $2.2 \pm 4.1 \mathrm{~mm} /$ year) ${ }^{20}$ Large entry tear $(>10 \mathrm{~mm})$ or tear located on the inner curvature has also been found to be associated with increased aortic growth rate on follow-up. ${ }^{10}$

\section{COMPLICATED ACUTE TYPE B AORTIC DISSECTION}

TBAD is considered complicated if there is evidence of rupture or malperfusion. ${ }^{21}$ In total, $20 \%$ to $30 \%$ of TBAD is deemed complicated and carries high mortality in the short term if left untreated. ${ }^{11,22}$

Open surgical repair for complicated TBAD has an operative mortality of $15 \%$ to $30 \%$, which can be as high as $50 \%$ in the presence of malperfusion. ${ }^{23} \mathrm{~A}$ smaller number of lamellae in the DTA than ascending aorta contributes to increased anastomotic bleeding after open repair. ${ }^{5,6}$ Location of proximal entry tear close to the origin of the 
left subclavian artery in most cases necessitates deep hypothermic circulatory arrest via left thoracotomy, attesting to the complexity of the operation. In their review of 59 patients undergoing open repair for complicated acute TBAD, Fattori and colleagues ${ }^{24}$ reported $40 \%$ in-hospital complication rate. The incidence of spinal cord ischemia was $6.8 \%$, with a stroke rate of $9 \%$.

Given poor survival with only medical treatment and a high rate of mortality and morbidity after open surgical repair, TEVAR is considered the gold standard in patients with acute complicated TBAD. ${ }^{6,25}$ The technical feasibility of TEVAR in patients with acute complicated TBAD was demonstrated by Ehrlich and colleagues ${ }^{26}$ in their review of 32 patients with coverage of primary tear in $87 \%$ of cases. A systematic review of 2531 patients undergoing TEVAR for acute complicated TBAD reported pooled 30-day mortality of $7.3 \%$. Pooled 30-day mortality for 2347 patients receiving BMT was $19 \% .^{27}$

Mossop and colleagues ${ }^{28}$ successfully introduced the concept of staged extension of a stent-graft with a baremetal stent to address false lumen flow distal to the stent to expand the true lumen and promote aortic remodeling. Nienaber and colleagues ${ }^{29}$ published a case series of $12 \mathrm{pa}$ tients with adjunctive or staged extension of TEVAR stent graft with a bare-metal scaffolding stent to address distal true lumen collapse and patent false lumen. They demonstrated a $100 \%$ success rate and avoided any spinal ischemia as the flexibility of using a bare-metal stent allowed them to use a shorter stent-graft used for covering the proximal tear site.

Investigators of the Study of Thoracic Aortic Type B Dissection Using Endoluminal Repair (STABLE I) trial, a multicenter prospective study of Zenith Dissection Endovascular System (William Cook Europe, Aps, Bjaeverskov, Denmark) for the treatment of patients with acute complicated TBAD, reported an impressive 30-day mortality of only $5.5 \%$ and 30 -day paraplegia rate of $1.8 \%{ }^{30}$ The pathology-specific composite device used was a combination of a stent-graft and a distal baremetal stent. In this trial, a bare-metal stent was only deployed when there was evidence of malperfusion or flow in the false lumen after placement of the stent-graft to cover the primary proximal tear site. Five-year results of the study showed $79.9 \pm 6.2 \%$ freedom from all-cause mortality and $83.9 \pm 5.9 \%$ freedom from dissectionrelated mortality. ${ }^{31}$ Complete false lumen thrombosis of the thoracic aorta was observed in $74.1 \%$ of patients at 5 years, and this translated into a statistically significant increase in true lumen diameter and a decrease in the size of the false lumen. Favorable aortic remodeling shown in this study was also evident from $65.5 \pm 7.5 \%$, and $92.2 \pm 3.9 \% 5$-year freedom from secondary intervention and aortic rupture respectively.

\section{SUBACUTE TYPE B AORTIC DISSECTION}

Steuer and colleagues, ${ }^{32}$ in their review of 60 patients undergoing TEVAR for complicated TBAD, reported that 1 in 6 patients developed complications like rupture, malperfusion, or rapid aortic expansion more than 14 days after the onset of symptoms. Extension of the vulnerable period beyond the first 14 days after the onset of symptoms could be a clue to the subsistence of a subacute phase in the natural history of TBAD. The subacute phase is proposed to extend from 2 weeks to 3 months from the onset of symptoms when the membrane is not fully mature and the patient is at risk of rapid disease progression. ${ }^{33}$ In a review of 22 patients who underwent TEVAR for the onset of complications in the subacute phase, there was no report of lowerextremity malperfusion, which might be due to progressive maturation and stabilization of the distal flap during this period. ${ }^{34}$ In this study by Steuer and colleagues, there was no report of early death or neurologic complications after TEVAR.

It is known that with gradual loss of the intimal septum's pliability with time, benefits of aortic remodeling with TEVAR are also decreased. While this is true for chronic dissection, which benefits mainly by promoting false lumen thrombosis, TEVAR in the subacute phase has been shown to induce aortic remodeling by false lumen collapse. ${ }^{35}$ INSTEAD trial, where 140 patients with uncomplicated TBAD in the subacute phase were randomized to receive only BMT or BMT with TEVAR, confirmed the feasibility of TEVAR in the subacute setting. There was no procedural mortality and proximal tear site was successfully covered in all the patients. ${ }^{12}$ In total, $88.9 \%$ of patients in the study had type IIIB TBAD, and control of blood pressure was achieved in $90 \%$ of cases. Five-year results of this trial (INSTEAD-XL) after intention-to-treat analysis reported significantly greater freedom from the combined point of progression and adverse events in the TEVAR group (aorta-related death, conversion, and ancillary interventions, including the second stent-graft procedure, access revision, peripheral interventions) (hazard ratio, 0.55; $0.32-0.98 ; P=.041) .{ }^{10}$ This study also showed the absence of disease progression in the TEVAR group after 2 years. This halt of disease progression in the TEVAR group was associated with aortic remodeling. TEVAR group experienced significant expansion of true lumen and shrinkage of the false lumen in the DTA. TEVAR group also showed complete thrombosis of the false lumen in $90.6 \%$ of cases at the thoracic level and total aortic remodeling in $79.2 \%$ of cases. This study showed stent-graft ability to change the natural history of TBAD by inducing aortic remodeling and resultant very low incidence of late reintervention in the TEVAR group, especially after the first year, compared with the BMT group, where subjects experienced continuous crossovers. 


\section{CHRONIC TYPE B AORTIC DISSECTION}

Winnerkvist and colleagues ${ }^{12}$ reported actuarial survival of $69 \%$ at 10 years in patients with uncomplicated TBAD on anti-impulse therapy. Progressive degeneration of the aorta with an average of $20 \%$ to $50 \%$ delayed expansion of the false lumen by 4 years was mostly responsible for this suboptimal survival. A review of 125 patients from the Vascular Quality Initiative Database who underwent TEVAR for chronic TBAD reported an in-hospital mortality rate of $2.4 \% .{ }^{36}$ Safety and feasibility of TEVAR in patients with chronic TBAD was also evident from a meta-analysis of 567 patients, which reported technical success in $89.9 \%$ of patients. ${ }^{37}$ At a median follow-up of 26.1 months, stroke and spinal cord injury were relatively low at $1.5 \%$ and $0.45 \%$, respectively. The INSTEAD trial, the only randomized trial of patients with uncomplicated TBAD who underwent TEVAR between 2 and 52 weeks after onset of symptoms, also reported $100 \%$ technical success in covering the primary tear and had no procedural mortality. ${ }^{35}$ A meta-analysis comparison of TEVAR with open surgical repair in patients with chronic TBAD reported significantly lower early mortality, stroke, spinal cord injury, and respiratory complications with TEVAR. ${ }^{38}$

The need for reintervention has been an Achilles heel after TEVAR in patients with chronic TBAD. In a retrospective review of 155 patients with chronic dissection, Alhussaini and colleagues ${ }^{39}$ reported reintervention rate of $26.5 \%$. Persistent flow in the false lumen is responsible for progressive degeneration leading to the expansion of the DTA and is a major risk factor for reintervention. Uncovered distal aortic fenestration and stent-graft induced new entry tears (SINE) were responsible for patency of the false lumen in majority of cases. The incidence of SINE requiring reintervention was as high as 3\% in this analysis. SINE was found to significantly negatively impact aortic remodeling in a review of 65 patients with chronic TBAD receiving TEVAR, where the incidence of SINE was $27.7 \% .^{40}$ Tear of the thickened nonpliable flap in patients with chronic TBAD has been postulated to cause SINE. Oversizing the stent-graft more than $10 \%$ and connective tissue disorder are the other risk factors for SINE. Type I endoleak is also a significant culprit requiring reintervention. However, in a prospective comparative study of TEVAR and BMT in patients with chronic TBAD, Jia and colleagues ${ }^{41}$ reported a $12 \%$ incidence of type I endoleak after TEVAR with spontaneous sealing in most patients during follow-up.

As discussed before in this article, 5-year results of the INSTEAD Trial (INSTEAD-XL) reported greater freedom from the combined point of progression and adverse events. ${ }^{10}$ The number needed to treat in this study was 13 . TEVAR group in the trial, where $88.9 \%$ of dissections were DeBakey type IIIB, showed impressive aortic remodeling with the significant expansion of the true lumen in DTA $(19.4 \pm 8.4$ to $32.6 \pm 5.5 \mathrm{~mm}$ at 5 years; $P<.0001)$, which was associated with significant shrinkage in false lumen diameter $(29.3 \pm 12.4$ to $10.4 \pm 13.2 \mathrm{~mm}$ at 5 years; $P<.0001)$. In comparison, the medical treatment group showed expansion of maximum aortic diameter ( $43.6 \pm 9.2$ to $56.4 \pm 6.8 \mathrm{~mm} ; P<.0001)$. TEVAR group also showed a greater rate of complete false lumen thrombosis of DTA (TEVAR: $90.6 \%$, medical: $22 \%$; $P<.0001)$. Lack of aortic remodeling in the BMT group translated into continued crossover and the need for intervention.

More evidence of ability of TEVAR to induce aortic remodeling in chronic TBAD came from a study from Yang and colleagues, ${ }^{42}$ where in a retrospective study of 61 patients with TBAD receiving TEVAR, there was no significant difference in the rate of complete false lumen thrombosis between patients with acute and chronic TBAD (chronic TBAD: $88.5 \%$, acute TBAD: $80.6 \%$; $P=.221$ ). Overall, these results suggest a potential salutary effect of TEVAR in subjects with chronic TBAD.

One important mode for treatment failure after TEVAR in patients with chronic TBAD is persistent retrograde perfusion of false lumen via septal fenestrations. This has been described as "type R" false lumen flow as per recently published Society for Vascular Surgery/Society of Thoracic Surgeons reporting standards for TBAD. ${ }^{17}$ Various techniques have been described to induce false lumen thrombosis in this setting, as we know that persistent false lumen flow is associated with treatment failure. ${ }^{8}$ Miletic and colleagues, ${ }^{43}$ in a report of 51 patients undergoing false lumen embolization for persistent retrograde false lumen flow, using iliac plugs, and coils, showed induction of false lumen thrombosis in nearly $90 \%$ of patients. Kölbel and colleagues $^{44}$ showed the feasibility and effectiveness of an innovative technique in a case series of 3 patients where they balloon dilated an oversized stent graft to rupture the dissection membrane and occlude the false lumen. Eleshra and colleagues, ${ }^{45}$ from the same group, also published a case series of 14 consecutive patients with retrograde false lumen flow, where they used Candy-Plug II (Cook Medical, Bjaeverskov, Denmark) device, and showed clinical success in $93 \%$ of patients. Candy-Plug II is a custom-made stent graft delivered through a 22-French delivery system and has a central channel which collapses and seals the false lumen as the device is deployed. However, these techniques are nascent in their development with application in limited populations and even more limited follow-up.

\section{LIMITATIONS OF TEVAR}

In a review of 404 patients with TBAD from the International Registry of Acute Aortic Dissection database, Nauta and colleagues ${ }^{46}$ reported $16 \%$ incidence of retrograde arch 
extension. The risk of paraplegia and stroke after TEVAR for TBAD continues to be a concern. Incidence of paraplegia after TEVAR is around $8 \%,{ }^{47}$ and although cerebrospinal fluid drainage provides protection against spinal cord ischemia, cerebrospinal fluid drainage procedure per se can be associated with serious complications. ${ }^{48}$ TEVAR is also a risk factor for stroke and rates can be as high as 14.3 in patients with Zone 2 stent-graft deployment without left subclavian artery revascularization. ${ }^{49}$ Acute increase in arterial stiffness as a result of stent graft in DTA has been found to increase the afterload on the heart. ${ }^{27}$

\section{CONCLUSIONS}

Evidence of the benefit of TEVAR in patients with TBAD is getting stronger with time. TEVAR has proved to be superior to open repair for patients with acute complicated TBAD, and is now a class 1 LOE A recommendation on the most recent Society of Thoracic Surgeons guidelines but is still a 1C recommendation in the latest European guidelines. ${ }^{50}$ Several studies have shown the feasibility and safety of TEVAR in the acute setting in patients with uncomplicated TBAD. TEVAR can provide maximum benefit in the acute phase when membrane is quite pliable and amenable to manipulation. Stent-graft mediated expansion of the true lumen and obliteration of the primary tear site can optimize aortic remodeling in the diseased segment of DTA. This can be evident as early as one year after TEVAR, as reported in the results of the ADSORB trial. TEVAR has been shown to improve long term results in patients with uncomplicated TBAD. However, there is no good long term RCT of BMT versus TEVAR for acute uncomplicated TBAD. ADSORB was too small, with short-term follow-up, to draw meaningful conclusions. This type of trial is desperately needed.

Multiple studies have shown benefits of TEVAR in the subacute phase and that true lumen can be expanded even late after the onset of disease. The INSTEAD-XL trial demonstrated that TEVAR can promote aortic remodeling in both subacute and chronic phase of TBAD, with resultant improved long-term survival and freedom from aorticrelated adverse events.

Given these promising results, and increasing evidence for TEVAR in management of TBAD, we anticipate that TEVAR will be more extensively used to treat this complex disease process. As the cardiovascular surgical community becomes more comfortable and confident in adopting endovascular skills, and as endograft technology continues to rapidly evolve and improve, the potential salutary effects of TEVAR for TBAD management may become more evident in the near future. These findings also attest to the importance of the cardiac surgical community to embrace and hone endovascular skills to remain engaged in a clinical space that is rapidly evolving.

\section{Conflict of Interest Statement}

The authors reported no conflicts of interest.

The Journal policy requires editors and reviewers to disclose conflicts of interest and to decline handling or reviewing manuscripts for which they may have a conflict of interest. The editors and reviewers of this article have no conflicts of interest.

\section{References}

1. Elefteriades JA, Lovoulos CJ, Coady MA, Tellides G, Kopf GS, Rizzo JA. Management of descending aortic dissection. Ann Thorac Surg. 1999;67:2002-5; discussion 2014-9.

2. Glower DD, Fann JI, Speier RH, Morrison L, White WD, Smith LR, et al. Comparison of medical and surgical therapy for uncomplicated descending aortic dissection. Circulation. 1990;82:39-46.

3. Davies RR, Goldstein LJ, Coady MA, Tittle SL, Rizzo JA, Kopf GS, et al. Yearly rupture or dissection rates for thoracic aortic aneurysms: simple prediction based on size. Ann Thorac Surg. 2002;73:17-27; discussion 27-8.

4. Nagai M, Makita S, Abiko A, Nakamura M. Factors related to long-term prognosis in medically treated type B aortic dissection: a physical predisposing factor Int Angiol. 2012;31:427-32.

5. Gallo A, Davies RR, Coe MP, Elefteriades JA, Coady MA. Indications, timing, and prognosis of operative repair of aortic dissections. Semin Thorac Cardiovasc Surg. 2005; 17:224-35.

6. Fattori R, Cao P, De Rango P, Czerny M, Evangelista A, Nienaber C, et al. Interdisciplinary expert consensus document on management of type B aortic dissection. J Am Coll Cardiol. 2013;61:1661-78.

7. Svensson LG, Kouchoukos NT, Miller DC, Bavaria JE, Coselli JS, Curi MA, et al. Expert consensus document on the treatment of descending thoracic aortic disease using endovascular stent-grafts. Ann Thorac Surg. 2008;85:S1-41.

8. Trimarchi S, Nienaber CA, Rampoldi V, Myrmel T, Suzuki T, Bossone E, et al Role and results of surgery in acute type B aortic dissection: insights from the International Registry of Acute Aortic Dissection (IRAD). Circulation. 2006;114(1 suppl):1357-64.

9. Fattori R, Montgomery D, Lovato L, Kische S, Di Eusanio M, Ince H, et al. Survival after endovascular therapy in patients with type B aortic dissection: a report from the International Registry of Acute Aortic Dissection (IRAD). JACC Car diovasc Interv. 2013;6:876-82.

10. Nienaber CA, Kische S, Rousseau H, Eggebrecht H, Rehders TC, Kundt G, et al Endovascular repair of type B aortic dissection: long-term results of the randomized investigation of stent grafts in aortic dissection trial. Circ Cardiovasc Interv. 2013;6:407-16.

11. Tsai TT, Trimarchi S, Nienaber CA. Acute aortic dissection: perspectives from the International Registry of Acute Aortic Dissection (IRAD). Eur J Vasc Endovasc Surg. 2009;37:149-59.

12. Winnerkvist A, Lockowandt U, Rasmussen E, Rådegran K. A prospective study of medically treated acute type B aortic dissection. Eur J Vasc Endovasc Surg. 2006;32:349-55

13. Brunkwall J, Kasprzak P, Verhoeven E, Heijmen R, Taylor P, Alric P, et al. Endovascular repair of acute uncomplicated aortic type B dissection promotes aortic remodelling: 1 year results of the ADSORB trial. Eur J Vasc Endovasc Surg. 2014;48:285-91.

14. Trimarchi S, Tolenaar JL, Jonker FH, Murray B, Tsai TT, Eagle KA, et al. Importance of false lumen thrombosis in type B aortic dissection prognosis. $J$ Thorac Cardiovasc Surg. 2013;145(3 suppl):S208-12.

15. Qin YL, Deng G, Li TX, Jing RW, Teng GJ. Risk factors of incomplete thrombosis in the false lumen after endovascular treatment of extensive acute type B aortic dissection. J Vasc Surg. 2012;56:1232-8.

16. Xiang D, Kan X, Liang H, Xiong B, Liang B, Wang L, et al. Comparison of midterm outcomes of endovascular repair and medical management in patients with acute uncomplicated type B aortic dissection. J Thorac Cardiovasc Surg. 2021; 162:26-36.e1.

17. Qin YL, Wang F, Li TX, Ding W, Deng G, Xie B, et al. Endovascular repai compared with medical management of patients with uncomplicated type B acute aortic dissection. J Am Coll Cardiol. 2016;67:2835-42.

18. Ray HM, Durham CA, Ocazionez D, Charlton-Ouw KM, Estrera AL, Miller CC 3rd, et al. Predictors of intervention and mortality in patients with uncomplicated acute type B aortic dissection. J Vasc Surg. 2016;64:1560-8. 
19. Tolenaar JL, van Keulen JW, Jonker FH, van Herwaarden JA, Verhagen HJ, Moll FL, et al. Morphologic predictors of aortic dilatation in type B aortic dissection. J Vasc Surg. 2013;58:1220-5.

20. Tolenaar JL, van Keulen JW, Trimarchi S, Jonker FH, van Herwaarden JA, Verhagen HJ, et al. Number of entry tears is associated with aortic growth in type B dissections. Ann Thorac Surg. 2013;96:39-42.

21. Lombardi JV, Hughes GC, Appoo JJ, Bavaria JE, Beck AW, Cambria RP, et al. Society for Vascular Surgery (SVS) and Society of Thoracic Surgeons (STS) reporting standards for type B aortic dissections. J Vasc Surg. 2020;71:723-47.

22. Coady MA, Ikonomidis JS, Cheung AT, Matsumoto AH, Dake MD, Chaikof EL, et al. Surgical management of descending thoracic aortic disease: open and endovascular approaches: a scientific statement from the American Heart Association. Circulation. 2010;121:2780-804.

23. Brandt M, Hussel K, Walluscheck KP, Böning A, Rahimi A, Cremer J. Early and long-term results of replacement of the descending aorta. Eur J Vasc Endovasc Surg. 2005;30:365-9.

24. Fattori R, Tsai TT, Myrmel T, Evangelista A, Cooper JV, Trimarchi S, et al. Complicated acute type B dissection: is surgery still the best option? A report from the International Registry of Acute Aortic Dissection. JACC Cardiovasc Interv. 2008;1:395-402.

25. Grabenwöger M, Alfonso F, Bachet J, Bonser R, Czerny M, Eggebrecht H, et al. Thoracic endovascular aortic repair (TEVAR) for the treatment of aortic diseases: a position statement from the European Association for Cardio-Thoracic Surgery (EACTS) and the European Society of Cardiology (ESC), in collaboration with the European Association of Percutaneous Cardiovascular Interventions (EAPCI). Eur Heart J. 2012;33:1558-63.

26. Ehrlich MP, Dumfarth J, Schoder M, Gottardi R, Holfeld J, Juraszek A, et al Midterm results after endovascular treatment of acute, complicated type B aortic dissection. Ann Thorac Surg. 2010;90:1444-8.

27. Moulakakis KG, Mylonas SN, Dalainas I, Kakisis J, Kotsis T, Liapis CD. Management of complicated and uncomplicated acute type B dissection. A systematic review and meta-analysis. Ann Cardiothorac Surg. 2014;3:234-46.

28. Mossop PJ, McLachlan CS, Amukotuwa SA, Nixon IK. Staged endovascular treatment for complicated type B aortic dissection. Nat Clin Pract Cardiovasc Med. 2005;2:316-21; quiz 322.

29. Nienaber CA, Kische S, Zeller T, Rehders TC, Schneider H, Lorenzen B, et al. Provisional extension to induce complete attachment after stent-graft placement in type B aortic dissection: the PETTICOAT concept. J Endovasc Ther. 2006;13: 738-46.

30. Lombardi JV, Cambria RP, Nienaber CA, Chiesa R, Mossop P, Haulon S, et al. Aortic remodeling after endovascular treatment of complicated type B aortic dissection with the use of a composite device design. J Vasc Surg. 2014;59: 1544-54.

31. Lombardi JV, Cambria RP, Nienaber CA, Chiesa R, Mossop P, Haulon S, et al. Five-year results from the Study of Thoracic Aortic Type B Dissection Using Endoluminal Repair (STABLE I) study of endovascular treatment of complicated type B aortic dissection using a composite device design. J Vasc Surg. 2019; 70:1072-81.e2.

32. Steuer J, Eriksson MO, Nyman R, Björck M, Wanhainen A. Early and long-term outcome after thoracic endovascular aortic repair (TEVAR) for acute complicated type B aortic dissection. Eur J Vasc Endovasc Surg. 2011;41:318-23.

33. Dake MD, Thompson M, van Sambeek M, Vermassen F, Morales JP. DISSECT: a new mnemonic-based approach to the categorization of aortic dissection. Eur $J$ Vasc Endovasc Surg. 2013;46:175-90.

34. Steuer J, Björck M, Mayer D, Wanhainen A, Pfammatter T, Lachat M. Distinction between acute and chronic type B aortic dissection: is there a sub-acute phase? Eur J Vasc Endovasc Surg. 2013;45:627-31.
35. Nienaber CA, Kische S, Akin I, Rousseau H, Eggebrecht H, Fattori R, et al. Strategies for subacute/chronic type B aortic dissection: the investigation of stent grafts in patients with type B aortic dissection (INSTEAD) trial 1-year outcome. J Thorac Cardiovasc Surg. 2010;140(6 suppl):S101-8; discussion S142-6.

36. Conway AM, Qato K, Mondry LR, Stoffels GJ, Giangola G, Carroccio A. Outcomes of thoracic endovascular aortic repair for chronic aortic dissections. J Vasc Surg. 2018;67:1345-52.

37. Thrumurthy SG, Karthikesalingam A, Patterson BO, Holt PJ, Hinchliffe RJ, Loftus IM, et al. A systematic review of mid-term outcomes of thoracic endovascular repair (TEVAR) of chronic type B aortic dissection. Eur J Vasc Endovasc Surg. 2011;42:632-47.

38. Boufi M, Patterson BO, Loundou AD, Boyer L, Grima MJ, Loftus IM, et al. Endovascular versus open repair for chronic type B dissection treatment: a MetaAnalysis. Ann Thorac Surg. 2019;107:1559-70.

39. Alhussaini M, Arnaoutakis GJ, Scali ST, Giles KA, Fatima J, Back M, et al. Impact of secondary aortic interventions after thoracic endovascular aortic repair on long-term survival. Ann Thorac Surg. 2020;110:27-38.

40. Huang CY, Hsu HL, Chen PL, Chen IM, Hsu CP, Shih CC. The impact of distal stent graft-induced new entry on aortic remodeling of chronic type B dissection. Ann Thorac Surg. 2018;105:785-93.

41. Jia X, Guo W, Li TX, Guan S, Yang RM, Liu XP, et al. The results of stent graft versus medication therapy for chronic type B dissection. J Vasc Surg. 2013;57: 406-14.

42. Yang CP, Hsu CP, Chen WY, Chen IM, Weng CF, Chen CK, et al. Aortic remodeling after endovascular repair with stainless steel-based stent graft in acute and chronic type B aortic dissection. J Vasc Surg. 2012;55:1600-10.

43. Miletic KG, Kindzelski BA, Hodges KE, Beach J, Tong MZ, Bakaeen F, et al. Impact of endovascular false lumen embolization on thoracic aortic remodeling in chronic dissection. Ann Thorac Surg. 2021;111:495-501.

44. Kölbel T, Carpenter SW, Lohrenz C, Tsilimparis N, Larena-Avellaneda A, Debus ES. Addressing persistent false lumen flow in chronic aortic dissection: the knickerbocker technique. J Endovasc Ther. 2014;21:117-22.

45. Eleshra A, Kölbel T, Tsilimparis N, Panuccio G, Scheerbaum M, Debus ES, et al. Candy-Plug Generation II for false lumen occlusion in chronic aortic dissection: feasibility and early results. $J$ Endovasc Ther. 2019;26:782-6.

46. Nauta FJ, Tolenaar JL, Patel HJ, Appoo JJ, Tsai TT, Desai ND, et al. Impact of Retrograde arch extension in acute type B aortic dissection on management and outcomes. Ann Thorac Surg. 2016;102:2036-43.

47. Amabile P, Grisoli D, Giorgi R, Bartoli JM, Piquet P. Incidence and determinants of spinal cord ischaemia in stent-graft repair of the thoracic aorta. Eur J Vasc Endovasc Surg. 2008;35:455-61.

48. Riambau V, Capoccia L, Mestres G, Matute P. Spinal cord protection and related complications in endovascular management of B dissection: LSA revascularization and CSF drainage. Ann Cardiothorac Surg. 2014;3:336-8.

49. Bradshaw RJ, Ahanchi SS, Powell O, Larion S, Brandt C, Soult MC, et al. Left subclavian artery revascularization in zone 2 thoracic endovascular aortic repair is associated with lower stroke risk across all aortic diseases. J Vasc Surg. 2017; 65:1270-9.

50. Erbel R, Aboyans V, Boileau C, Bossone E, Bartolomeo RD, Eggebrecht H, et al. 2014 ESC guidelines on the diagnosis and treatment of aortic diseases: document covering acute and chronic aortic diseases of the thoracic and abdominal aorta of the adult. The task force for the diagnosis and treatment of aortic diseases of the European Society of Cardiology (ESC). Eur Heart J. 2014;35: 2873-926.

Key Words: type B aortic dissection, endovascular therapy 


\section{Bibliography: Type B Aortic Dissection: Recent Articles from AATS Journals}

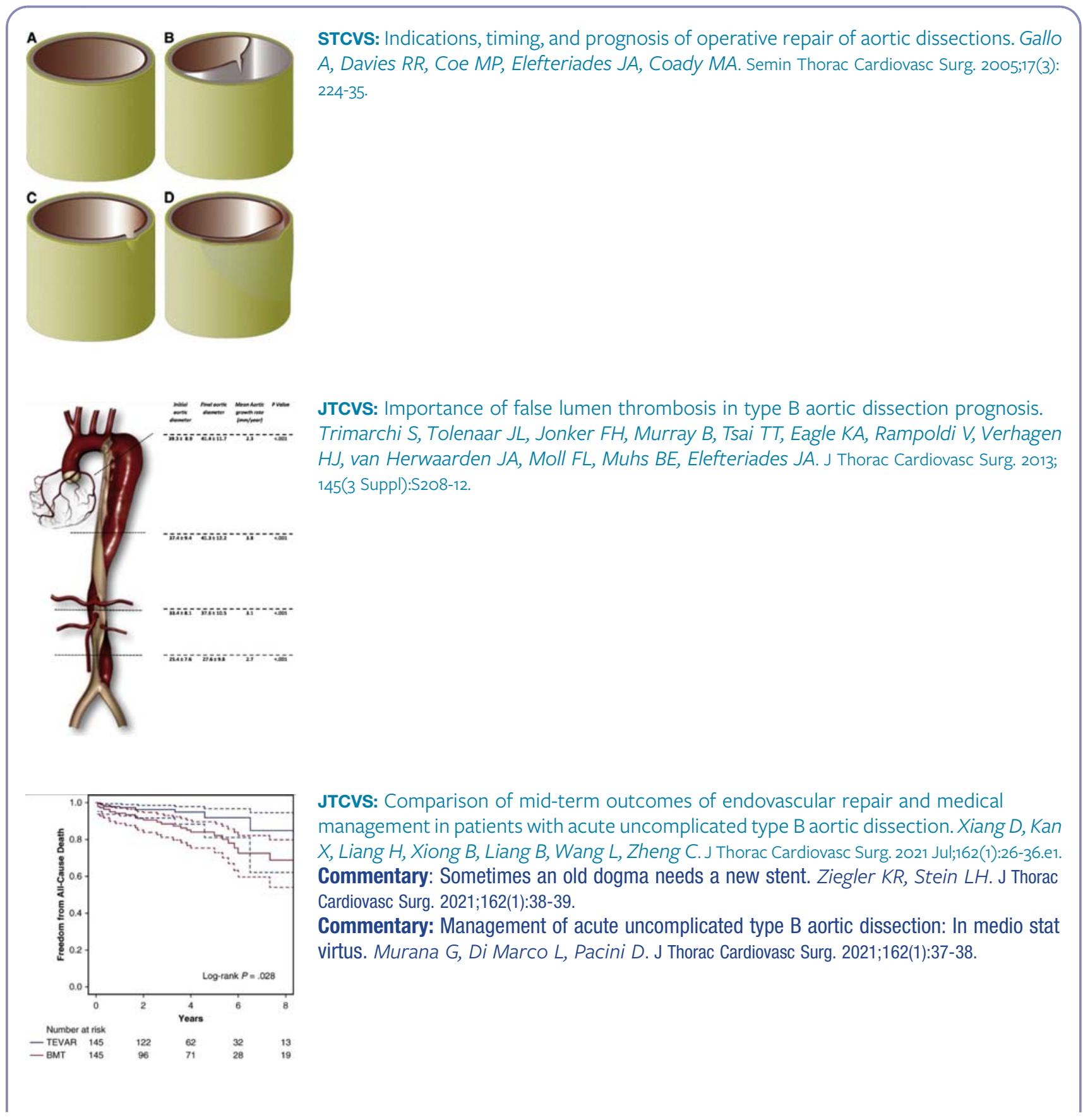




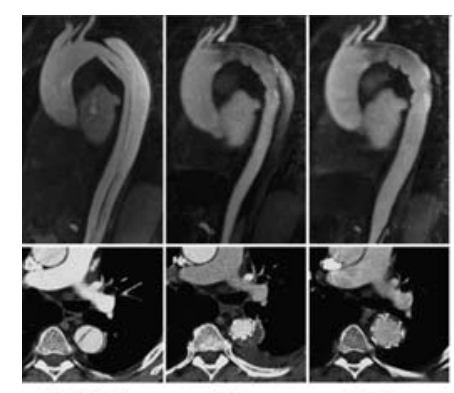

JTCVS: Strategies for subacute/chronic type B aortic dissection: The Investigation Of Stent Grafts in Patients with type B Aortic Dissection (INSTEAD) trial 1-year outcome. Nienaber CA, Kische S, Akin I, Rousseau H, Eggebrecht H, Fattori R, Rehders TC, Kundt G, Scheinert D, Czerny M, Kleinfeldt T, Zipfel B, Labrousse L, Ince H. J Thorac Cardiovasc Surg. 2010;140(6 Suppl):S101-8. 